\title{
Challenges in Advanced Dementia
}

\author{
Esther Chang and Amanda Johnson \\ University of Western Sydney, \\ Australia
}

\section{Introduction}

This chapter presents the significant challenges in practice health professionals' face in providing care to people with advanced dementia. These challenges constitute all facets of care giving inclusive of physical, psychological and spiritual care. Worldwide advanced dementia is an increasingly burdensome health issue. People with advanced dementia have substantial care needs at the end of their life (Birch \& Stokoe, 2010). The Alzheimer's Disease International report (2010) stated there were 35.6 million people living with dementia. The report estimates the number of people living with dementia worldwide will increase to 65.7 million by 2030 and 115.4 million by 2050 (Alzheimer's Disease International, 2010). Further the majority of people will live in low and middle income countries (Alzheimer's Disease International, 2010). In 2010, the financial burden of dementia was costed at US\$ 604 billion (Alzheimer's Disease International, 2010). The Alzheimer's Disease International, 2010 report predicts that "these costs account for around $1 \%$ of the world's gross domestic product, varying from $0.24 \%$ in low income countries, to $0.35 \%$ in low, middle income countries, $0.50 \%$ in high, middle income countries, and $1.24 \%$ in high income countries" (Alzheimer's Disease International, 2010, p.5).

A high proportion of people with dementia need some level of care to supplement their cognitive decline. This care can range from minimal support of individual activities for example, shopping to a full range of personal care. As the person declines and the disease progresses total supervision necessitating $24 \mathrm{hr}$ care across 7 days per week, of all activities of daily living, is required. The Alzheimer's Disease International, 2010 report states that the cost of informal care (unpaid) provided by families and the direct costs of care by health professionals in residential aged care facilities, equates to being the world's $18^{\text {th }}$ largest economy (Alzheimer's Disease International, 2010). Evidence also suggests that a lack of training, education and support for both health professionals and informal caregivers is still present (Chang, et al., 2005; Chang, et al., 2009). Thus the challenges before the community are significant and need to be responded to in a planned, informed and educated manner so that people dying from dementia can be the recipients of quality care at the end of their life.

\section{Dementia}

Dementia is a progressive, incurable disorder severely limiting an individual's functional ability and quality of life (Access Economics, 2009). It is a collective term used to describe a series of symptoms resulting from impaired cognitive function that affect the person's 
memory, thinking, behaviour, psychological capacity and the ability to perform activities of daily living (Emre, 2009; Sampson, 2009). After age 65, the likelihood of developing dementia roughly doubles every five years (Alzheimer's Disease International, 2010). For people aged 65 years or older, more than $10 \%$ are affected by dementia (McKeel, Burns, Meuser \& Morris, 2007). Alzheimer's disease is the most frequently experienced type of dementia [31\%] followed by: vascular dementia [22\%], dementia with Lewy bodies [11\%] and the fronto-temporal lobar degeneration dementias [7.8\%] (Sampson, 2009). The disease trajectory for dementia is protracted and is considered to unfold over a series of stages. These stages consist of mild, moderate and severe. The proportion of Americans aged 65 years and older with mild dementia represented $28 \%$ in 2010 (with a projected decrease to $23 \%$ in 2050); moderate dementia represented $31 \%$ in 2010 (with a projected decrease to $29 \%$ in 2050) and severe dementia represented $41 \%$ in 2010 (with a projected increase to $48 \%$ in 2050) (Alzheimer's Association, 2010). These percentages provide insight into not only the prevalence of the disease but also the escalating need for palliative care to play a role.

\subsection{Advanced dementia}

Advanced dementia is the term used to denote a combination of both the severe and end stages of this disease. This term refers to progressive immobility and reduced capacity for self care; poor nutrition resulting from reduced fluid and liquid intake; infections related to immobility; skin breakdown and general debilitation (Shuster, 2000). Recognition of dementia as a terminal disease has been slow and it is only now that a body of evidence is emerging upon which to base practice (Chang et al., 2008; Hancock et al., 2006). In the USA, Alzheimer's disease ranks as the sixth leading cause of death (Alzheimer's Association, 2011). Of greater significance and impact on the worldwide community is the reported $66 \%$ increase in death rates from dementia as compared to all other leading causes of death which have declined (Alzheimer's Association, 2011). Further people dying from dementia are reported to have the presence of a co-morbid condition in 19\% or higher of cases (Moss, Braunschweig, \& Rubinstein, 2002). Thus the provision of care in this context is multifactorial and complex (Sampson, 2010). This context demonstrates the requirement for an educated and skilled staff in the provision of palliative care principles to provide care to the person dying from dementia to ensure their needs and those of the family are adequately met (Chang, et al., 2005; Chang, et al., 2009; Chang \& Walter, 2010; Johnson, et al., 2009).

Recent acknowledgement of dementia as a terminal illness has been made by recognising that it is a disease in which a steady deterioration occurs that leads to death (Albinsson, \& Strang, 2002; Mitchell, et al., 2009). This recognition has come about because advanced dementia is now perceived to have a similar symptom burden and prognosis to advanced cancer (Sampson, 2010). Further acknowledgement of dementia as a terminal illness is made with researchers providing evidence of the need for the principles of palliative care to be applied to those suffering from dementia along with those who have a diagnosis of incurable cancer (Fulton et al., 2011). It is argued that the application of palliative care principles makes an important contribution to the comfort of the person with dementia and the family's wellbeing and that this introduction should occur much earlier on in the dementia illness trajectory (Fulton et al., 2011). However Chang and Walter (2010) assert that few people in nursing homes or long term care facilities with advanced dementia are recognised as being 'at risk' for death. They claim that until advanced dementia is formally diagnosed as a terminal illness, the lack of prognostication will serve as a barrier to the principles of palliative care being applied in this context (Chang \& Walter, 2010). Banerjee \& 
Owen (2009) report that only $1 / 3$ of people are ever formally provided a diagnosis of dementia which therefore exacerbates an already difficult care situation for health professionals to know when to intervene with palliative care principles, as it lies substantially unacknowledged.

\subsection{Palliative care}

In the following section we will examine the dying trajectory for a person with advanced dementia. The trajectory presents a multitude of symptoms and behaviours affecting the person's mind, body and spirit which poses many challenges for family members and health professionals. Failure to identify and address these needs may mean the person dying and their family will have unmet needs leading to physical, emotional, mental and spiritual distress and the diminished capacity for healthy bereavement in family members following the death of the person with dementia. Incorporating a holistic approach to care ensures that these unmet needs are addressed and appropriate interventions implemented to promote quality care at the end of life for all involved.

\subsubsection{Holistic approach to caring for a person with advanced dementia}

In striving for a holistic approach to care and a healthy state we need balance and harmony in all aspects of the person's life - physical, social, emotional, cognitive and spiritual to be present irrespective of the presence or absence of physical disease and mental illness. A person's wholeness is the dynamic interaction of the mind, body and spirit components within the person, between and among others and with the universe (Erickson, 2007, p.140). When a holistic approach to care is adopted in advanced dementia the journey taken by both the, informal carer, health professional and the person is of a healing nature. Healing is a core element to a palliative care philosophy which promotes harmony and balance in the terminal phase of a person's illness.

Adopting a holistic approach in caring for the person with advanced dementia necessitates health professionals responding also to the needs of family members. Providing palliative care is centred on the family unit and involves those individuals who are defined by the dying person as being significant to them (Johnson, 2012). The dementia trajectory frequently means family members have been involved over a long period of time and provided much of the care until relocation to a residential aged care facility. The constant exposure by family members to the person's declining cognitive state may be expressed as anticipatory grief or pre death before the actual physical death of the person occurs (Sampson, 2010). Recognising how families are feeling and coping with their loss and grief has a direct impact on the person with dementia which often contributes to their anxiety, depression, wandering and other displays of behaviour. Addressing the physical, intellectual, emotional and spiritual needs, within the cultural context of the family unit, is as equally important as those of the person dying (Johnson, 2012). The relationships fostered between the health professionals, the person with advanced dementia and their family may facilitate healing restoring a degree of harmony and balance. If a holistic care is not adopted significant levels of distress and suffering may be experienced by the person and their families (Maher \& Hemmings, 2005) which may manifest as behavioural issues in the person with advanced dementia and unhealthy bereavement in family members. Practising in this way demonstrates a shift of care from being disease orientated to prioritising the needs of the person and their family above all else ( $\mathrm{O}^{\prime}$ Brien King \& Gates et al., 2007). 
Principles underpinning holistic care involve the understanding of the person as a unique human being who interacts with their environment and recognises a need for healing in cases where there is no cure but where the emphasis is on promoting comfort and alleviating suffering (Mitchell et al., 2009). Most importantly for the health professional is giving care that values compassion, respect, trust, and authenticity to promote healing. Johnson et al (2011) suggest that the role of the health professional should initially focus on managing the physical symptoms because if these needs are not addressed it would be problematic to address their psycho-social and spiritual needs. Health professionals who take account of the complexity of need manifested in the person with advanced dementia demonstrate their commitment to the concept of holism.

The pathology of advanced dementia means that there will be many challenges and disruptions along the illness trajectory resulting in the manifestation of several symptoms and behaviours that can affect the body, mind and spirit of the person (Johnson et al., 2011). These symptoms and behaviours are further exacerbated by the presence of co-morbid conditions that culminate in death (Evans \& Goodman, 2009). Dementia often follows functional decline with the person suffering disability throughout the last year of life with substantial impact on activities of daily living. Maximising the person's quality of life is the primary goal for health professionals. This can be better supported by more accurate prognostication of the need for palliative care intervention and recognising the value of palliation at different points of the trajectory (Fulton et al., 2011; Hallberg, 2006).

\subsubsection{The application of palliative care principles}

The provision of palliative care to people dying only with a cancer diagnosis has shifted. In Australia, the provision of quality care at the end of life must be available for all people regardless of location, age, income, diagnosis and prognosis, social and cultural background (Palliative Care Australia[PCA], 2008). The Australian view expressed resonates also with the UK, USA and many other countries (Birch \& Stokoe, 2010). Research provides evidence that the symptoms experienced by a person dying are similar regardless of the underlying pathology (Sampson, 2009). This evidence suggests the broadening of palliative care to include all life limiting illnesses in practice is warranted. Dementia is one of those chronic life limiting illnesses now seen as benefiting from the application of palliative care principles (Birch \& Stokoe, 2010; Chang et al., 2009). Escalation of numbers of people dying worldwide from dementia also means a heightened interest in palliative care in this context (Birch \& Stokoe, 2010; Sampson. 2009). Further with a greater emphasis on symptom management and supportive care, the role of palliative care is recognised as being instituted as early as the time of diagnosis and at any other point along the illness trajectory, in accordance with the needs of the person dying and their family. No longer is it confined to the 'terminal phase of an illness' or 'at the end of life' as palliative care has much to offer in alleviating the suffering and promoting comfort of a person in a multitude of disease trajectories. Specifically Panke \& Volicer (2002), confirm that the most critical symptoms decreasing quality of life and comfort in people with advanced dementia are behavioural symptoms and pain. Implementing care underpinned by this broader view means the principles of palliative care can be provided within a variety of care settings: acute care, aged care, community and hospices (Haley \& Daley, 2008) supplemented by assistance from specialist palliative care services and colleagues (Johnson et al., 2011). This is particularly so for people with advanced dementia. Chang \& Walter (2010) highlight that the symptoms exhibited by a person in the terminal phase of dementia required nursing home intervention on $90 \%$ of 
occasions, and $70 \%$ of all dementia related deaths, in the USA occur in nursing homes (Fulton et al., 2011). In Australia over 50, 000 older people die in residential aged care facilities annually (Australian Institute of Health and Welfare [AIHW], 2010a) and the government response has been to target better end of life care through the up skilling of the aged care workforce through education to meet this need (PCA, 2011). These figures provide evidence of the escalating need for sound knowledge and skills in palliative care to have a presence in settings where people with a non-cancer related diagnosis are cared.

Thus palliative care, as described by the World Health Organisation [WHO] (2005), is an approach to care that improves the quality of life of patients and their families facing the problem associated with a life-limiting illness, through the prevention and relief of suffering by means of early identification and impeccable assessment and treatment of pain and other problems, physical, psychosocial and spiritual and:

- $\quad$ provides relief from pain and other distressing symptoms;

- affirms life and regards dying as a normal process;

- intends neither to hasten or postpone death;

- $\quad$ integrates the psychological and spiritual aspects of patient care;

- offers a support system to help patients live as actively as possible until death;

- offers a support system to help the family cope during the patients illness and in their own bereavement;

- $\quad$ uses a team approach to address the needs of patients and their families, including bereavement counselling, if indicated;

- will enhance quality of life, and may also positively influence the course of illness;

- is applicable early in the course of illness, in conjunction with other therapies that are intended to prolong life, such as chemotherapy or radiation therapy, and includes those investigations needed to better understand and manage distressing clinical complications.

Chang et al (2009) have long advocated the need for staff to have superior skills in assessment, pain and symptom management and negotiation of care with family. Further improved knowledge about the dementia trajectory, the principles of palliative care and advance care directives and their role in caring for the person dying with dementia are needed (Chang, et al., 2009). Fulton et al (2011) argue that people dying with dementia are a highly vulnerable group because of a high rate of co-morbidity, inability to participate and understand their care situation and a reliance on caregivers to act as their advocates. The need therefore to keep people dying from dementia in an aged care setting (nursing home, residential aged care facility or long term care) with appropriate palliative interventions is paramount to eliminating the need to transition to other care settings. Transitioning to other care settings in this group is identified as a major complication (Fulton et al., 2011) that might precipitate adverse events culminating in death. In summary the importance of recognising dementia as a life limiting illness and the benefits afforded by the application of palliative care principles to this group of people cannot be underestimated (Sampson, 2010; van der Steen, 2010).

\section{Symptom management}

Dying in the $21^{\text {st }}$ century has become more complex and protracted as a result of modern medicine typically taking 30 months from the time a terminal diagnosis is confirmed to die (Old \& Swagerty, 2007). However, a person dying from dementia has spent many years in a progressive and steady functional decline leading to an increased dependency on caregivers to support them in their activities of daily living. This functional decline may also 
manifest in the person as suffering with a severe disability. Further, given the age of the person with dementia, it is highly probable that at least one co-morbid condition is present concurrent to their primary dementia diagnosis (AIHW, 2010b). The breadth of symptoms displayed combined with their presentation, reveals caring for the person dying from dementia to be a challenging and complex environment requiring a knowledgeable and skilled workforce to deliver care (Hennings, Froggatt \& Keady, 2010). The symptom breadth and presentation are magnified as a consequence of the person being older person with the high probability of co-morbidity and a reduced reserve capacity combined with a disease which manifests with severe functional decline. Therefore instituting a philosophy of palliative care into practice has the potential to promote quality of life by mitigating the impact of factors that may reduce quality of life (Hallberg, 2006). The focus of care becomes reorientated to managing symptoms as opposed to the actual disease itself (Hallberg, 2006).

People dying from a chronic, life limiting illness, such as dementia, where curative and restorative outcomes are no longer viable frequently share a common cluster of symptoms at the end of their life regardless of the underlying pathology (Johnson et al., 2006). This cluster of symptoms include: fatigue, pain, nausea with or without vomiting, constipation and dyspnoea (Johnson et al., 2006). If left unmet these symptoms have the greatest potential to adversely affect the quality of living the person dying experiences and limits the capacity of their family to engage in normal grief (Johnson, et al., 2006). Evidence is now emerging which shows that the symptom burden between those dying with dementia to be comparable to those dying with a cancer diagnosis. A retrospective study identified pain, dyspnoea, agitation, fatigue, eating problems such as difficulty in swallowing (McCarthy et al., 1997) to be present in those dying from dementia. More recently Mitchell, et al's (2009) 18 month prospective study of 323 nursing home residents confirmed that advanced dementia is a terminal illness which leads to aspiration pneumonia or eating difficulties in the final stages and last few months of life. Specifically while much commonality exists, Pautex et al's (2007) study showed that fatigue is frequently not reported in dementia patients and suggests this is because it is less prevalent or infrequently noticed. It may however be that the person dying with dementia is unable to express this need and therefore it goes unreported. Many studies report that pain and shortness of breath (dyspnoea) to be the most frequently occurring symptoms commonly experienced by people dying from dementia (Fulton et al., 2011; McCarthy et al., 1997; Pautex et al., 2007). The complexity in which care is delivered is magnified further by the person with dementia's cognitive impairment acting as a significant impediment to discerning what the symptoms are, how best to manage them and if they remain unmet. This impediment to symptom management lies primarily in those who are dying from dementia (though other neurodegenerative diseases and cerebral cancers may also fit into this category) making them a highly vulnerable group not able to access and be recipients of quality symptom management. This vulnerability further heightens the need for a superior skilled aged care workforce to deliver palliative care (Chang et al., 2009; PCA, 2011).

The following section provides a brief overview of the symptoms commonly experienced in a person with advanced dementia.

\subsection{Pain}

The presence of pain or discomfort in the person dying from dementia is further complicated by the individual's inability to articulate their pain. Pain has been reported to occur in $21 \%$ to $83 \%$ of all dementia patients, at some point along the disease trajectory 
(Zwakhalen et al., 2009). Further the presence of pain is identified as increasing as death approaches (Williams, et al, 2005). Pain may be displayed by the person with advanced dementia in the form of: agitation; restlessness; facial grimacing; moaning or an alteration in their respiratory rate and pattern and resistive behaviours (Panke \& Volicer, 2002; Sampson, 2010). However, while pain is common in people with advanced dementia it frequently goes under-detected and under-treated (Fulton et al., 2011; Sampson, 2010). Two main reasons co-exist for this under-detection and under-treating. The first is poor assessment knowledge and skill in the health professional and the second is the communication difficulties a person with advanced dementia experiences which become further magnified as the disease progresses (Sampson, 2010). While a complex entity, this should not mitigate this symptom being adequately managed (van der Steen, 2010).

\subsection{Eating and swallowing}

Difficulties with eating and swallowing usually signify the person with dementia has transitioned into the final stage of the disease trajectory with months to a year of life remaining (Fulton et al., 2011). Mitchell et al's (2009) revealed an eating problem was present in $85.8 \%$ of 323 nursing home residents that they studied. The study further identified that in the last 3 months of their life the prevalence of an eating problem rose to a level of $90.4 \%$.

\subsection{Dyspnoea}

Shortness of breath or dyspnoea increasingly appears in people with advanced dementia as they approach death in half to three quarters of all individuals (van der Steen, 2010). This rate of prevalence is comparable to those people with a terminal cancer (van der Steen, 2010). Shortness of breath in the person with advanced dementia is attributed to pneumonia as consequence to aspiration (Mitchell et al., 2009; van der Steen, 2010). Mitchell et al's (2009) study reported high and increasing level of aspiration were present as the person with dementia neared death. For families, as well as the person shortness of breath causes much discomfort and distress (Johnson, et al., 2006; Johnson, 2012).

\subsection{Behavioural}

The presence of behavioural and psychological symptoms is as high as $90 \%$ of people with dementia at some point in their illness trajectory (Sampson, 2010). It remains a challenging problem in caring for people with dementia in general ( Bidewell \& Chang, 2011). In advanced dementia specifically Mitchell et al., (2009) identified over half of their study participants remained agitated and distressed. Behavioural symptoms may be displayed as passivity and withdrawal, resisting care in a verbal and or physical manner and may constitute an expression of discomfort within the person's environment and or actual physical discomfort (Panke \& Volicer, 2002) that they are unable to express due to an impaired communication ability resulting from dementia. Examples could include but are not limited to: feeling cold; hungry; in pain, constipated or having a full bladder. A person with advanced dementia is unable to verbalise their feelings and therefore the presence of these stimuli indicate a level of discomfort escalating to pain which necessitates an alternative means of expression usually displayed in the form of aggressive and resistive behaviours (Sampson, 2010). Of interest is that agitation is less frequently assessed for in the final stage of a person's life with advanced dementia as pain and shortness of breath became the overriding symptom family members in particular are concerned about (van der Steen, 2010). 


\subsection{Infections}

In people with advanced dementia the presence of infections becomes more prevalent (Sampson, 2010). Mitchell et al's (2009) study revealed over an 18 month period pneumonia $(41 \%)$ and a febrile episode (53\%) were most common. Sampson reports that the febrile episode is mostly likely to be a urinary tract infection. Burns et al (1990) had previously reported that up to $71 \%$ of deaths in people with advanced dementia were most likely attributed to these two infections (Burns et al., 1990). The presence of infections in people with advanced dementia, are attributed to the person being immobile, bed bound, at increased risk for aspiration and an impaired immunological system (Sampson, 2010).

To illustrate the comparable nature of symptoms experienced by a person with advanced dementia and someone dying from cancer the following case study is presented:

Caroline Hegarty is my patient today. She is a 70 year old woman. On reading her notes I know she is dying. A cascade of symptoms is present which provide me with the trigger indicating she is dying. The staff are increasingly needed to perform and or support her Activities of Daily Living and now she is completely dependent on them. Her appetite has been intermittent for weeks and has now declined to the point where she is unable or unwilling to eat. An assessment on other causes for a depressed appetite has been conducted and there is little evidence of swallowing difficulties present. Two weeks ago she commenced on thickened fluids but since Monday Caroline has displayed little interest in these. Further she has become increasingly lethargic and has been difficult to arouse in the last 48hours. Previously Caroline had been very restless and would frequently walk the corridors but now she seems to have lost her restlessness and seems at peace. When I last saw Caroline two weeks ago she could raise her head to take the thickened fluids now she doesn't have the energy to hold her head up and to swallow.

In summary this case study attempts to illustrate that regardless of the underlying pathology, in essence when a person is actively dying a common cluster of symptoms are present for all people to a lesser or greater degree.

\subsection{Management of symptoms}

Under treatment of symptoms at the end of a person's life with dementia is a major concern (van der Steen 2010). This is largely due to the lack of recognition of dementia as a terminal illness and the person's cognitive decline and impaired communication. While Mitchell et al's (2009) study confirmed that advanced dementia was indeed a terminal illness it also highlighted the lack of referral to hospice as compared to those with another terminal disease despite the obvious presence of pain and dyspnoea in the last 3 months of life. In her study only $29 \%$ of the cohort received hospice intervention (Mitchell, et al., 2009). This poses significant challenges for family and health professionals in managing the symptoms, as a result of the dying process. Chang \& Walter cite as evidence of the lack of application of palliative care interventions as: the underuse of advanced care planning; the overuse of tube feeding; the inadequate management of dyspnoea, pain, agitation and aspiration symptoms (2010, p. 1107). The management of these symptoms is complex, requiring a structured approach using a range of therapeutic interventions (Sampson, 2010). In particular the impaired communication experienced by the person with advanced dementia may potentially inhibit palliative care interventions (Johnson et al., 2009). 


\section{Communication skills in the provision of care with advanced dementia and their families}

\subsection{The need for effective communication}

One of the goals in palliative care is to encourage open communication which leads to a positive attitude to death and dying. Effective communication in this context must address the cultural, social, psychological and spiritual aspects of a person and their family, so that their needs are met. Achieving this goal assists in reducing a person's suffering and managing their symptoms that leads to improved quality of care (Johnson et al., 2009).

\subsection{Knowledge about dementia among family caregivers}

International studies highlight an inadequacy in the quality and quantity of dementia information which is given to people with dementia and their family members particularly in the latter stages of dementia (Birch \& Draper, 2008; Sampson, 2010). In many instances they might feel uncomfortable in asking questions of health professionals (Chang et al., 2010).

\subsection{Complexity of knowledge and skills provision that impacts on communication}

Communicating with the family is one of the greatest challenges faced by health professionals. There is the need to frequently discuss end of life issues directly with the family in the absence of the person with advanced dementia because of the cognitive decline associated with dementia that ultimately results in impaired communication.

The authors conducted a study with key professional providers of care to examine the challenges with caring for people with advanced dementia. The study was informed by a qualitative framework based on action research. Action research collects information from key stakeholders and provides ongoing feedback to participants, thereby facilitating change that improves practice (Kemmis \& McTaggart, 1988). Data collection was through five focus groups and 20 individual in-depth interviews. Participants were drawn from the key groups of professional providers of care in an outlying urban area of Sydney, Australia, which includes three local government areas having a total population of 320,000 . The five focus group included general practitioners, palliative care speciality staff, palliative care volunteer managers and volunteers, aged or dementia specialist health care professionals and residential aged care facility staff. The data attest to the complexity of caring for people with advanced dementia living in residential aged care facilities, and the associated challenges for key professional carers. The main areas of challenge identified were: knowledge and skills in the direct provision of care, knowledge relating to dementia as a disorder, and knowledge relating to palliation. Participants in this study emphasized the need for improvements in knowledge and skills, and the need for policy changes (Chang, et al., 2009, p.42). From this study, it was recommended that professionals of care need to have skills in assessment, pain, and symptom management, and negotiation of care with the family. Advance care plans and directives will assist clinical decision -making when an individual can no longer communicate. Negotiations between family members and the multidisciplinary care team to achieve consensus about the goals of care might improve resident comfort by ensuring that symptoms are controlled without unnecessary, burdensome interventions (Chang, et al., 2009 p.46). 


\subsection{Advance care planning}

Advanced care planning involves the assessment of the person and family needs and to identify and discuss care options across the illness trajectory in the context of the person's preferences (Mariano, 2007). In the context of people with advanced dementia, they experience progressively declining cognitive function which impedes their capacity to make decisions about their care (Sampson, 2010). Therefore it is advocated that advance care planning for this group of people occur early on in the disease trajectory as compared to other diseases (Sampson, 2010). Importantly this will allow for the personal characteristics and behaviour of the individual to be understood and to tailor the interventions to support the person's symptoms, behaviour and coping mechanisms of the person and their family in the palliative context. The person with advanced dementia is progressing towards the terminal phase when death will occur. The problems described in this section usually require the person responsible (lawful substituted decision maker) to make decisions about treatments including whether or not to use certain life prolonging medical treatments. It may be considered that certain life prolonging treatments (Mitchell et al., 2009) may not add to the comfort or quality of life of the person with advanced dementia (Palliative Care Dementia Interface: Enhancing Community Capacity Project, 2011).

At a community level, people generally do not understand dementia well and negative attitudes can exist. In the face of this, family caregivers of someone diagnosed with dementia face many challenges in both itself and informing a realistic picture of what to expect and the nature of dementia, especially in the advanced stages. Responding to a highlighted need by family care givers to be given basic information about dementia progression (Chang et al., 2006), the authors developed a booklet entitled, Information for Families and Friends of People with Severe and End Stage Dementia (Palliative Care Dementia Interface: Enhancing Community Capacity Project, $1^{\text {st }}$ edition, 2006), in consultation with dementia and aged care experts. This 41 page booklet provided information about what to expect as dementia progresses, including cognitive ability, functional ability (sleep cycle, walking, incontinence, eating and swallowing), behaviours and emotions, physical symptoms (pain, weight loss, infections, changes in limb movements), end of life issues and palliative care options that can be discussed with health professionals, the dying process, what to expect at the time of death and where to obtain ongoing support (Chang et al., 2009.) More recently the $3^{\text {rd }}$ edition of this booklet included important aspects of advanced care planning (Palliative Care Dementia Interface: Enhancing Community Capacity Project, 2011) in response to acknowledging advanced dementia as a terminal illness. Clearly, improved knowledge, gained by the provision of additional information relevant to the family caregiver, has a role to play in improving this situation.

\subsection{The importance of the family carer role in planning care for the person with advanced dementia}

Advance care planning is all about talking about the future care of the person with advanced dementia. The point of talking about future care for a person living with advanced dementia is that medical care for both expected and unexpected health issues can be considered well before a crisis. In this way, decisions can be made calmly, based on what the person with dementia's wishes would be if they could talk for themselves. Misunderstandings and possible areas of conflict can be dealt with so everyone comes to a clear and agreed understanding about the care to be given to the person with dementia. 
Usually a number of advance care planning discussions are needed. Key times when discussion might be held are when the person with dementia is diagnosed with a new medical condition that will impact on their health, after a hospital admission, or on admission to a residential care facility. Topics that might be discussed, depending on the circumstances, include:

- The values, wishes, beliefs and expectations of the person with dementia regarding what quality of life means to them. The person responsible and other family and friends contribute by recalling conversations and events where the person with dementia indicated their beliefs.

- The role and importance of the person responsible as a substitute decision maker. This person needs to "put themselves in the shoes of the person in dementia" and make decisions from the person's viewpoint.

- The understanding of everyone involved about the dementia diagnosis, and what will happen in the future.

- The benefits and risks of any treatment options.

- The goal of care, so the person with dementia will have the best possible quality of life, with their wishes respected.

- $\quad$ The person with dementia's preferences for end of life care.

Making decisions about another person's care and treatment options is a major responsibility. Some families prefer more than one person to help with the decision making. However, the person responsible is the person who legally can consent to, or refuse consent for, any treatment, so that the person has the final say. By involving other family members in advance care planning discussions, the person responsible can make sure everyone concerned understands the issues and the reasons for decisions. (Chang et al., 2009). The more the person responsible and family members know about dementia and the changes that occur over time, the more likely it is that the person with dementia will receive care that respects their wishes and improves comfort and quality of life. Further involvement of family members at key decision points assists them to understand about the multiple losses they have experienced in relation to the person with dementia and the anxiety their care causes for them (Hennings, Froggatt \& Keady, 2010). The person that is responsible for care needs to be encouraged to ask questions and discuss with their health professional. Ideally, advanced care planning should be encouraged in the earlier stages of dementia when a person is still competent to make decisions about what is important to them communicate and their preferences (Sampson, 2010).

\section{Conclusion}

Advanced dementia brings numerous somatic, affective and behavioural symptoms, impairments and co-morbidities. Diagnosing and managing pain and symptoms in people with advanced dementia is often made difficult by communicative difficulties of a person with dementia. Adopting a systematic and holistic approach to assessment and management of pain and other symptoms means that people with advanced dementia are more likely to receive appropriate care. These challenges point to the professional development and training needs for dementia care staff, so that patients/residents with dementia and their carers' expectations are met. Advanced care directives expressing the resident's prospective care preferences would give clinicians' clearer guidelines for responding to patients, and would assist in negotiating care decisions with family members. 
There is also a pressing need for investing in research which explores various models of care for people with advanced dementia, from the health professional and caregivers' perspectives, in relation to their cost effectiveness and suitability for practice. Only by investing in research and providing the evidence can governments and health care services improve the lives of people with dementia and those who care for them. Implementing palliative care for people with dementia makes an important contribution to their comfort and promotes healthy grieving in family members while at the same time attempting to minimise the impact of stress for all concerned.

\section{References}

Access Economics. (2009). Keeping dementia front of mind: Incidence and prevalence 2009-2050. Retrieved from http://www.alzheimers.org.au/research-publications/accesseconomics-reports.asp April 7th 2011.

Albinsson, L. \& Strang, P. (2002). A palliative approach to existential issues and death in end-stage dementia care. Journal of Palliative Care, 18(3), pp. 168-175.

Alzheimer's Association (2010). Changing the trajectory of Alzheimer's disease: A national imperative. Alzheimer's Association: Chicago

Alzheimer's Association. (2011). 2011 Alzheimer's disease facts and figures report. Retrieved from http://www.alz.org/alzheimers_disease_facts_andfigures.asp on 7th April 2011.

Alzheimer's Disease International (2010). World Alzheimer Report 2010 The Global Economic Impact of Dementia, Alzheimer's Disease International accessed via www.alz.co.uk on $7^{\text {th }}$ April 2011.

Australian Institute of Health and Welfare (2010a). Australia's Health 2010. AIHW: Canberra

Australian Institute of Health and Welfare (2010b). Residential aged are in Australia 2008 2009 a statistical overview. Aged care statistics series no. 31 Cat no Age 62, AIHW: Canberra

Banerjee, S. \& Owen, J. (2009). Living well with dementia. A national dementia strategy. London: Department of Health

Bidewell, J. Chang, E., (2010). Managing dementia agitation in residential aged care. Dementia 2011, 10(3), pp. 299-315

Birch, D. \& Stokoe, D. (2010). Caring for people with end-stage dementia. Nursing Older People, pp. 22(2) 31-36

Birch, D. \& Draper, J. A. (2008). A critical literature review exploring the challenges of delivering effective palliative care to older people with dementia. Journal of Clinical Nursing, 9, pp.1144-1163

Burns, A., Jacoby, R., Luthert, P. et al. (1990). Cause of death in Alzheimer's disease. Age Ageing, 19, pp. 341-4

Chang, E., Easterbrook, S., Hancock, K., Johnson, A., \& Davidson, P. (2010). Evaluation of an information booklet for caregivers of people with dementia: An Australian perspective. Nursing and Health Sciences, 12, pp.45-51

Chang, E. M., Daly, J., Johnson, A., Harrison, K., Easterbrook, S., Bidewell, J., Stewart, H., Noel, M., Hancock, K. (2009). Challenges for professional care of advanced dementia. International Journal of Nursing Practice, 15(1), pp.41-47.

Chang, E., Johnson, A., Easterbrook, S., Harrison, K. \& Luhr, M. (2008). Dementias. In: Chang, E. \& Johnson, A. (Eds.). Chronic Illness and Disability: Principles for Nursing Practice. Elsevier: Sydney 
Chang, E., Hancock, K., Harrison, K., Daly, J., Johnson, A., Easterbrook, S., Noel, M., LuhrTaylor, M., Davidson, P.M. (2005). Palliative care for end-stage dementia: A discussion of the implications for education of health professionals. Nurse Education Today, pp. 25(4),pp. 326-332

Chang, A. \& Walter, L.C. (2010). Recognizing dementia as a terminal illness in nursing home residents. Archives of Internal Medicine, 170(13), pp. 1107-1109

Emre, M. (2009). Classification and diagnosis of dementia: a mechanism-based approach. European Journal of Neurology, 16, pp. 168-173

Erickson, H.L. (2007). Philosophy and theory of holism. Nursing Clinics of North America, 42(2), 139-163

Evans, C. \& Goodman, C. (2009). Changing practice in dementia care for people in care homes towards end of life. Dementia, 8, pp. 424-431

Fulton, A.T., Rhodes-Kropf, J., Cocoran, A.M., Chau, D. \& Castillo, E.H. (2011). Palliative care for patients with dementia in long-term care. Clinical Geriatric Medicine, 27, pp. 153-170

Hancock, K., Chang, E., Johnson, A., Harrison, K., Daly, J., Easterbrook, S., Noel, M., Davidson, P. (2006) Palliative care for people with advance dementia: the need for a collaborative evidence-based approach. Alzheimers's Care Quarterly, 7(1), pp. 49-57.

Haley, C. \& Daley, J. (2008). Palliation in chronic illness. In: A. Johnson \& E. Chang (Eds.). Chronic illness and disability. Principles for nursing practice. Elsevier: Chatswood, pp. 168-184.

Hallberg, I.R. (2006). Palliative care as a framework for older people's long term care. International Journal of Palliative Nursing, 12, 5, pp. 224-229

Hennings, J., Froggatt, K. \& keady, J. (2010). Approaching the end of life and dying with dementia in care homes: the accounts of family carers. Reviews in Clinical Gerontology, 20, pp. 114-127

Johnson, A. (2012). Working with Families. In M. O'Connor, S. Aranchia \& S. Lee (eds.). Palliative Care: A guide to Practice. Victoria: Ausmed

Johnson, A., Chang, E., Daly, J., Harrison, K., Noel, M., Hancock, K., Easterbrook, S. (2009).The communication challenges faced in adopting a palliative care approach in advance dementia. International Journal of Nursing Practice, 15, pp. 467- 474

Johnson, A., Harrison, K., Currow, D., Luhr-Taylor, M., \& Johnson, R. (2006). Chapter 17: Palliative Care and Health Breakdown. In E. Chang, J. Daly \& D. Elliot (Eds.), Pathophysiology Applied to Nursing Practice, pp. 448-471 Elsevier: Sydney:

Johnson, C., Girgis, A., Paul, C., Currow, D.C., Adams, J. \& Aranda, S. (2011). Australian palliative care providers' perceptions and experiences of the barriers and facilitators to palliative care provision. Support Cancer Care, 19, pp. 343-352

Kemmis, S. \& McTaggert, R. (1988). The action research planner (3rd edn.). Geelong, Victoria: Deakin University Press

McCarthy, M., Addington-Hall, J., \& Altman, D. (1997). The experience of dying with dementia: A retrospective study. International Journal of Geriatric Psychiatry, 12, pp. 404-409

McKeel. D.W., Burns, J.M, Meuser, T.M. 7 Morris, J.C. (2007). An atlas of investigation and diagnosis. Dementia. Clinical publishing: United Kingdom

Maher, D. \& Hemmings, L. (2005). Understanding patient and family: holistic assessment in palliative care. British Journal of Community Nursing. 10(7), pp. 318-322

Marinano, C. (2007). Holistic nursing as a specialty: Holistic nursing - scope and standards for practice. Nursing Clinics of North America, 42(2), pp. 165-188 
Mitchell, S.L., Teno, J.M., Kiely, D.K. (2009). The clinical course of advanced dementia. New England Journal of Medicine, 361(16), pp. 1529-1538

Moss, M., Braunschweig, H., \& Rubinstein, R. (2002). Terminal care for nursing home residents with dementia (ethics). Alzheimer's Care Quarterly, 3(3), pp. 233-249

Old, J.L. \& Swagerty, D.L. (2007). A practical guide to palliative care. Lippincott Williams \& Wilkins: Philadelphia

Palliative Care Australia (2008). Strategic plan 2008-2011. Palliative Care Australia: Deakin, $\mathrm{ACT}$

Palliative Care Australia (2011). Caring for older Australians: Productivity Commission Draft Report. Palliative Care Australia: Deakin, ACT

O'Brien King, M. \& Gates, M.F. (2007). Teaching holistic nursing: The legacy of nightingale. Nursing Clinics of North America, 42(2), pp. 309-333

Palliative Care Dementia Interface: Enhancing Community Capacity Project, (2006). Information for families and friends of people with severe and end stage dementia, University of Western Sydney: Sydney

Palliative Care Dementia Interface: Enhancing Community Capacity Project. (2011) Information for families and friends of people with severe and end stage dementia ( $3^{\text {rd }} \mathrm{edn}$.). University of Western Sydney: Sydney ISBN 0957756836

Panke, J.A. \& Volicer, L. (2002). Caring for persons with dementia: A palliative approach. Journal of Hospice and palliative Nursing, 4(3), pp. 143-149

Pautex, S., Hermann, F.R., Le, L.P., Ghedira, M., Zulian, G.B., MIchon, A., \& Gold, G. (2007). Symptom relief in the last week of life: is dementia always a limiting factor? Journal of American Geriatric Society, 55, pp. 1316-1317

Sampson, E. (2010). Pallliative care for people with dementia. British Medical Bulletin, 96,1, pp. 159-174

Sampson, E., Blanchard, M., Jones, L., Tookman, A. \& King, M. (2009). Dementia in the acute-hospital: prospective cohort study of prevalence and mortality. British Journal of Psychiatry, 195, pp. 61-66

Shuster, J. (2000). Palliative care for advanced dementia. Clinical Geriatric Medicine, 17, pp. 377-391

van der Steen, J. (2010). Dying with dementia: What we know after more than a decade of research. Journal of Alzheimer's Disease, 22, pp. 37-55.

Williams, C.S., Zimmerman, S., Sloane, P.D., \& Reed, P.S. (2005). Characteristics associated with pain in long-term care residents with dementia. Gerontologist, 45, Spec no1, pp. 68-73

World Health Organisation (2005). Definition of palliative care. World Health Organisation: Geneva

Zwakhalen, S.M., Koopmans, R.T., Geels, P.J., Berger, M.P., \& Hamers, J.P. (2009). The prevalence of pain in nursing home residents with dementia measured using observational pain scale. European Journal of Pain, 13, pp. 89-93 


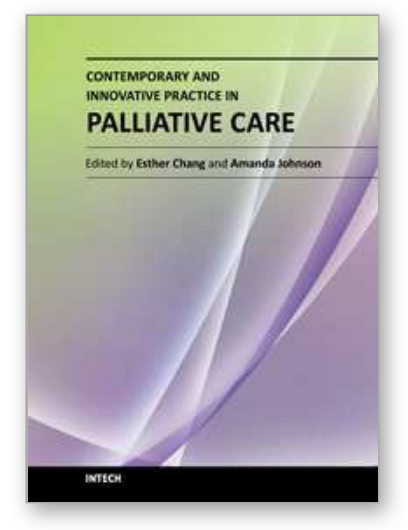

\author{
Contemporary and Innovative Practice in Palliative Care \\ Edited by Prof. Esther Chang
}

ISBN 978-953-307-986-8

Hard cover, 302 pages

Publisher InTech

Published online 10, February, 2012

Published in print edition February, 2012

This book is designed to provide a comprehensive insight unto the key and most prevalent contemporary issues associated with palliation. The reader will find viewpoints that are challenging and sometimes discerning, but at the same time motivating and thought-provoking in the care of persons requiring palliation. This book is divided into three sections. Section 1 examines contemporary practice; Section 2 looks at the challenges in practice; Section 3 discusses models of care. This book is an excellent resource for students, practising clinicians and academics. By reading the book, reflecting on the issues, challenges and opportunities ahead, we hope it will create within the reader a passion to take on, explore and further develop their palliative care practice.

\title{
How to reference
}

In order to correctly reference this scholarly work, feel free to copy and paste the following:

Esther Chang and Amanda Johnson (2012). Challenges in Advanced Dementia, Contemporary and Innovative Practice in Palliative Care, Prof. Esther Chang (Ed.), ISBN: 978-953-307-986-8, InTech, Available from: http://www.intechopen.com/books/contemporary-and-innovative-practice-in-palliative-care/challenges-inadvanced-dementia

\section{INTECH}

open science | open minds

\author{
InTech Europe \\ University Campus STeP Ri \\ Slavka Krautzeka 83/A \\ 51000 Rijeka, Croatia \\ Phone: +385 (51) 770447 \\ Fax: +385 (51) 686166 \\ www.intechopen.com
}

\author{
InTech China \\ Unit 405, Office Block, Hotel Equatorial Shanghai \\ No.65, Yan An Road (West), Shanghai, 200040, China \\ 中国上海市延安西路65号上海国际贵都大饭店办公楼405单元 \\ Phone: +86-21-62489820 \\ Fax: +86-21-62489821
}


(C) 2012 The Author(s). Licensee IntechOpen. This is an open access article distributed under the terms of the Creative Commons Attribution 3.0 License, which permits unrestricted use, distribution, and reproduction in any medium, provided the original work is properly cited. 